\title{
NIHILISMO, NIHILISTAS. SOBRE UNA POSIBLE FUENTE DE NIETZSCHE
}

\author{
Nihilism, Nihilists. On a Possible Source of Nietzsche
}

\author{
Carlo Gentili \\ Universidad de Bolonia
}

\begin{abstract}
Resumen: El artículo trata de las fuentes del concepto de «nihilismo» en Nietzsche. Es bien conocido que el término «nihilismo» adquiere un significado filosófico gracias a Nietzsche. Martin Heidegger y en menor medida Karl Löwith han contribuido luego a la transformación filosófica final del término. Sin embargo es igualmente bien conocido que Nietzsche no es el creador del término/concepto. La literatura secundaria sobre el tema nos informa que Nietzsche probablemente tomó prestado el término/concepto de la mediación literaria proporcionada por Turgeniev y Dostoevskij. El artículo tiene como objetivo mostrar que la reflexión de Nietzsche sobre el tema del nihilismo comenzó antes se su lectura de Dostoevkij (otoño-invierno 1884/1888) y al menos al mismo tiempo que él lee a Turgeniev (segunda mitad de los años 70). A fin de justificar esta retroactividad, el artículo mostrará fuentes nuevas e inexploradas en la Nietzsche-Forschung, tales como una novela escrita por Karl Gutzkow y un libro del teólogo Hermann Reuter.
\end{abstract}

Palabras clave: Nietzsche - nihilismo - fuentes - Gutzkow - Reuter

Aвstract: The paper deals with the sources of Nietzsche's concept of "nihilism". It is well known that the term "nihilism" obtains a philosophical meaning thanks to Nietzsche. Martin Heidegger and to a lesser extent Karl Löwith have then contributed to the final philosophical transformation of the term. Nevertheless it is equally well known that Nietzsche is not the creator of the term/concept. The secondary literature on the topic informs us that Nietzsche probably borrowed the term/concept from the literary mediation provided by Turgenev and Dostoevskij. The paper aims at showing that Nietzsche's reflection upon the theme of nihilism began well before his reading of Dostoevskij (autumn-winter 1887/1888) and at least at the same time as he read Turgenev (second half of the ' 70 s). In order to justify this backdating, the paper will show new and unexlopered sources in the Nietzsche-Forschung such as a novel by the writer Karl Gutzkow and a book by the theologian Hermann Reuter.

Keywords: Nietzsche - Nihilism - Sources - Gutzkow - Reuter 


\section{HEIDEGGER COMO PRÓLOGO}

Entre todas las posibles etiquetas bajo las cuales se ha intentado recoger el sentido complexivo de la filosofía de Nietzsche, ninguna, ha tenido probablemente más fortuna, sobre todo en los últimos decenios, que el término «nihilismo». No hay duda de que esto se ha debido, en gran parte, a la interpretación de Martin Heidegger. Él recoge bajo el título El nihilismo europeo (adoptando el título que Nietzsche había dado al fragmento, articulado en 16 proposiciones, escrito el 10 de junio de 1887 durante una estancia en el pueblo de Lenzerheide, no lejos de Sils Maria ${ }^{1}$ ), el curso que impartió en 1940, publicado después en $1961^{2}$, junto a otros, en dos volúmenes sobre Nietzsche. La lectura de Heidegger se mueve a partir de una de las definiciones de Nietzsche - «Nihilismo: falta la meta; falta la respuesta al "por qué" iqué significa nihilismo? - que los valores supremos se desvalorizan» (9[35], KSA $12,350)^{3}$ - para enlazar inmediatamente después el tema de los valores con el del ser: «La pregunta por el valor y su esencia tiene su fundamento en la pregunta por el ser» ${ }^{4}$. Esto le permite relacionar el tema nietzscheano del nihilismo con todo el desarrollo del pensamiento occidental, con referencias generalizadas a Descartes, y encuadrar a Nietzsche en el desarrollo de la «historia del ser», determinada por el desconcierto de la «diferencia ontológica», de la que él representaría el capítulo final en cuanto «cumplimiento de la metafísica». La interpretación del nihilismo nietzscheano se inscribe de tal modo en el marco de la pregunta por la «nada», que había interesado a Heidegger desde la conferencia pública impartida en la Universidad de Friburgo el 29 de julio de $1929^{5}$.

Este no es el lugar para discutir lo que realmente se refiere a Nietzsche en esta interpretación, en la que, como se ha observado siempre sobre la base de las palabras del mismo Heidegger, Nietzsche asume los rasgos de un problema del pensamiento. Sin embargo, si hay un aspecto decisivo en la lectura de Heidegger, es el haber sustraído el concepto de nihilismo a su pronunciamiento exclusivamente psicológico. No por casualidad, uno de los puntos centrales de la interpretación heideggeriana se mueve en realidad en

1 5[71], KSA 12, 211-217. FP IV 164

2 M. Heidegger, Nietzsche, Neske, Pfullingen 19895, vol. II, pp. 31-256.

3 FP IV 241:9 [35]. Las palabras que utiliza Heidegger, que cita siguiendo el texto de la Voluntad de poder, tienen un orden ligeramente diverso, cfr. M. Heidegger, op. cit., p. 45.

4 Ibid, p. 47.

5 M. Heidegger, Was ist Metaphysik?, ver en Id., Wegmarken, Frankfurt am Main: Klostermann, 19782, pp. 103-121. El escrito concluye con la nueva presentación de la célebre pregunta planteada por Leibniz: «¿Por qué en general el ente y no más bien la nada?» (ibid., p. 121); cfr. G.W. Leibniz, Principes de la nature et de la grâce fondés en raison (1714), § 7: «¿Por qué hay más bien cosas y no nada?». 
torno a un fragmento de noviembre de 1887 - marzo de 1888, en el cual el mismo Nietzsche describe el nihilismo como un «estado psicológico» que se presenta en tres formas, caracterizadas todas ellas por una naturaleza común reactiva. La primera forma es la consecuencia de haber «buscado en todo acontecer un 'sentido' que no se encuentra en él: de manera que el buscador acaba perdiendo el coraje». El nihilismo es, en este caso, «llegar a ser consciente del prolongado derroche de fuerza». La segunda «se da [...] cuando se ha supuesto una totalidad, una sistematización, incluso una organización, en todo acontecer y bajo todo acontecer»; el alma se exalta entonces «en la representación global de una forma suprema de dominio y de administración». Se pueden ver veladas referencias a Hegel en estas premisas a la decepción nihilista: «Si es el alma de un lógico, la absoluta extracción correcta de consecuencias y la dialéctica real son ya suficientes para reconciliarse ( $\mathrm{um}$ [...] zu versöhnen) con todo»; y a Spinoza: «Una especie de unidad, una forma cualquiera de "monismo"» que, infundiendo el «sentimiento de conexión y de dependencia de un todo que le supera infinitamente, se presenta como un modus de la divinidad ${ }^{6}$. Una tal idea exige «la entrega de lo individual» para «el bien de lo universal»; de ello se sigue, inevitablemente, la decepción: «... pero he aquí que ¡no existe semejante entidad universal!». El nihilismo es, aquí, la pérdida, por parte del hombre, de la «fe en su valor». La tercera forma de nihilismo consiste, finalmente, en la reacción a la huida hacia la metafísica:

6 Es frecuente en Nietzsche la proximidad de Spinoza y Hegel, la mayoría de las veces bajo el signo común negativo. En un fragmento de otoño de 1887, en el que aparecen expresiones muy similares las contenidas en el fragmento que estamos comentando en el texto, tal proximidad se desarrolla gracias a la mediación de Goethe: «El modo de pensar de Hegel no es muy lejano al de Goethe: escúchese lo que dice Goethe sobre Spinoza. Voluntad de divinización del todo y de la vida para encontrar quietud y felicidad en su contemplación y su examen; Hegel ve la razón por todas partes, - ante la razón está permitido resignarse y conformarse. En Goethe una especie de fatalismo casi alegre y confiado, que no se rebela, que no desfallece, que busca construir a partir de sí una totalidad, una creencia de que sólo en la totalidad todo se redime, aparece como bueno y justificado» (9[178], KSA, 12, 443; FP IV 282). En el aforismo 346 (Nuestro signo de interrogación) del libro V de La gaya ciencia, se señala el desencanto nihilista como la consecuencia de una confianza otorgada a un diseño que une claramente, aunque mediante una alusión, a Spinoza y Hegel: «Nos hemos recocido y enfriado y endurecido en la comprensión de que nada acontece en el mundo de modo divino, ni siquiera con medida humana, de modo racional» ( $F W, \mathrm{KSA}, 3,580$; OC III 862). Donde es evidente que Nietzsche pone bajo un signo de continuidad el «deus sive natura» de Spinoza con el «todo lo que es real es racional» de Hegel. Él lee el lema de Spinoza en una línea de continuidad con el Cristianismo; de este modo, en un fragmento de junio-julio de 1885, Nietzsche culpa a la «nostalgia de creer que en cierto sentido [...] "vive el antiguo Dios", - aquella nostalgia de Spinoza que se expresa en los términos "deus sive natura" (él sintió incluso "natura sive deus")» (36[15], KSA, 11, 556-557; FP III 799); mientras, en un fragmento del otoño de 1885-otoño 1886, anota: «"Vuelta a la naturaleza" 1. Sus estaciones: en el trasfondo la ciega confianza cristiana (¡aproximadamente ya Spinoza, "deus sive natura”!)»; aludiendo también en este caso a desarrollos presumiblemente hegelianos: «El spinozismo, sumamente influyente: 1) Intento de darse por satisfecho con el mundo tal cual es» (2[131], KSA, 12, 131; FP IV 118). 
«no queda más escapatoria que condenar todo este mundo del devenir como engaño e inventar un mundo que se encuentra más allá de éste mismo como mundo verdadero». Desde la constatación de que este mundo verdadero ha sido construido «a partir exclusivamente de necesidades psicológicas» surge «la increencia en un mundo metafisico». No existe ninguna unidad o verdad que abarque la infinita multiplicidad del devenir; lo que determina la ausencia de valor del mundo: «la fe en las categorías de la razón es la causa del nihilismo - hemos medido el valor del mundo mediante categorías que se refieren a un mundo puramente fingido» (11[99], KSA, 13, 46-49; FP IV 395).

Precisamente es en esta tercera forma en la que Heidegger se inspira para no limitar el concepto de nihilismo a un origen solamente psicológico. Habrá que plantearse la cuestión sobre lo que Nietzsche entiende por «psicológico» $\mathrm{y}$, después de haber excluido que él se refiera a cualquier investigación de carácter empírico, Heidegger excluye del mismo modo que ella pueda ser entendida como una «antropología», desde el momento en que la psicología, como Nietzsche la entiende, no pone al hombre en el centro de su consideración, sino que consiste, más bien, en «preguntar por lo "psíquico", es decir por el viviente en el sentido de la vida que determina todo devenir en el sentido de la "voluntad de poder"»; y, puesto que esta última constituye «el carácter fundamental de todo ente», «la "psicología" de Nietzsche equivale simplemente a metafísica» ${ }^{7}$.

Por lo tanto, si Heidegger emancipa de su carácter meramente reactivo lo que Nietzsche incluye en el ámbito de la psicología y de lo «psicológico», este resultado puede obtenerse solamente ampliando el ámbito de la psicología de su caracterización subjetiva y empírica al enraizamiento del hombre en el conjunto de lo ente. En una palabra, reconociendo a la psicología su significado filosófico. Aquí nos interesa menos el sentido completamente específico que Heidegger asigna a los conceptos de «metafísica» y de «filosofía», del hecho que, de este modo, se sale del todo del ámbito de la reactividad. Y puesto que, en la definición nietzscheana, es el nihilismo el que es definido como "estado psicológico", esto querrá decir que es posible atribuir al mismo nihilismo un estado filosófico desde su naturaleza originaria que esta definición determina.

\section{EL NIHILISMO ENTRE POLÍTICA Y LITERATURA}

Esto no parecería, en sí, un resultado significativo, desde el momento en que unánimemente se atribuye a Nietzsche la «invención» del concepto filosófico de nihilismo, por lo menos en el sentido que le atribuimos hoy, reconociéndole la paternidad de la conversión filosófica de un término que hasta aquel momento había conocido anteriormente un pronunciamiento

7 M. Heidegger, Nietzsche, op.cit., pp.60-61. 
político o literario. Sobre esta premisa, se da por descontado la filiación del concepto nietzscheano del nihilismo ruso, en su doble expresión política y literaria.

En este sentido, hay que observar que las primeras referencias a los «nihilistas» presentes en la obra de Nietzsche (sobre todo en el Nachlass) no permiten distinguir con precisión el ámbito político y el literario; aquel que se subraya es sobre todo la acción de los nihilistas sobre el terreno de la moral, en la que el resultado puede alcanzarse indistintamente a partir de los dos ámbitos. Así, por ejemplo, en un fragmento del verano de 1880 se define como una injusticia el hecho de que se honre «a quienes infringieron con el pensamiento el interdicto de las costumbres morales», mientras que «a quienes lo hicieron de hecho, se los denigra endosándoles motivos espurios». En realidad, a los «librepensadores deberían endosárseles los mismos motivos espurios», y se calla que «en el criminal podría encontrarse mucho valor y originalidad de espíritu, mucha independencia» - los mismos rasgos reconocidos evidentemente como virtud en los librepensadores - conduce a la distorsión de juicio para quien «hoy, a la pregunta de si los nihilistas rusos son, o no, más inmorales que los funcionarios rusos se responde de manera general en favor de los nihilistas». Pero son propiamente «los crímenes contra la moralidad de las costumbres» los que promueven nuestra crítica de la moral y, si «cualquiera atacaba lo existente era considerado un "hombre malo"», en realidad «ila historia sólo trata de tales hombres malos!» (4[108], KSA, 9, 127-128; FP II 564).

Nietzsche menciona el nihilismo ruso también en el aforismo 347 (Los creyentes y su necesidad de creer) del V libro de La gaya ciencia (1886-87), en el que estigmatiza aquella «necesidad de sostén, de respaldo, de apoyo» que puede encontrarse todavía, entre otros, «en el nihilismo según el modelo de San Petersburgo (es decir en la creencia en la no creencia, hasta llegar al martirio por ella)» ( $F W, \mathrm{KSA}, 3,582$; OC III 863). Es difícil establecer de modo definitivo qué es lo que entiende Nietzsche con este Nihilismus nach Petersburger Muster. Podría tratarse de una referencia genérica al hecho de que en San Petersburgo se había formado el círculo nihilista de Michail Vasil'evič Petraševskij (1821-1866), frecuentado también por Dostoevskij"; en este caso, la referencia al escritor no se referiría a su elaboración literaria del nihilismo. La «creencia en la no creencia, hasta llegar al martirio por ella» es una característica que parecería encajar perfectamente con la figura de Aleksej Nilič Kirillov, el nihilista de Los demonios que incita su ansia de

8 El 23 de abril de 1849 los afiliados al grupo fueron arrestados y condenados a muerte. La sentencia fue luego conmutada por el zar Nicolás I a una condena de trabajos forzados por vida en Siberia. Después de cuatro años, a los que se añadieron cinco años de servicio militar en un batallón de castigo, a Dostoevskij se le condonó la sentencia y pudo regresar a San Petersburgo. 
demostrar la no existencia de Dios hasta suicidarse para afirmar la propia liberación. Sin embargo, es casi seguro que Nietzsche haya leído la novela de Dostoevskij, en la traducción francesa publicada en 1886, no antes del otoñoinvierno de 1887-1888 : después, por tanto, de la redacción del V libro de $L a$ gaya ciencia, finalizada en octubre de 1886 . Podría aventurarse que la frase de Nietzsche contiene una alusión al personaje nihilista Bazarov, uno de los protagonistas de la novela de Turgenev, Padres e hijos. La «creencia en la no creencia» es una posible referencia a aquella «fe» atea en la ciencia, que es uno de los motivos recurrentes en La gaya ciencia ${ }^{10}$. Bazarov es el prototipo de nihilista que, si por un lado contrapone la utilidad de la ciencia frente a la pretendida inutilidad de la poesía y del arte, por otro lado no cree en realidad ni siquiera en la ciencia en abstracto como valor, sino solo en la utilidad de sus resultados ${ }^{11}$. Y es en nombre de esta utilidad como Bazarov encontrará la muerte, su martirio, a causa del tifus contraído después de haber curado a campesinos. Con un análisis muy preciso desde el punto de vista documental, Elisabeth Kuhn ha concluido que la lectura nietzscheana de la traducción francesa de Padres e hijos puede ser fechada entre 1876 y $1880^{12}$.

9 Cfr. P. Stellino, Nietzsche and Dostoevsky. On the Verge of Nihilism, Bern-Berlin-Bruxelles-Frankfurt am Main-New York-Oxford-Wien: Peter Lang, 2015, p. 119.

10 En el mismo aforismo 347 de La gaya ciencia Nietzsche observa que: «también ese impetuoso anhelo de certeza que se descarga hoy de modo científico-positivista en amplios sectores, el anhelo de querer tener algo firme», también esa es el «anhelo de sostén, de apoyo, en resumen, ese instinto de debilidad que ciertamente no crea las religiones, las metafísicas, las convicciones, pero sí - las conserva» ( $F W, \mathrm{KSA}, 3,581-582$; OC III 863).

11 En este sentido, es muy esclarecedor el diálogo de Bazarov con Pavel Petrovič Kirsanov, tío del amigo Arkadij Nikolàevič que se hospeda con la familia, el cual se convierte por el contrario en defensor de los valores de la tradición. A este que acaba de mencionar, aunque desfigurando los nombres, a Schiller y Goethe, Bazarov replica que «Un buen químico es veinte veces más útil que cualquier poeta». Y, a la pregunta de Pavel Petrovič sobre si él no reconoce el valor del arte, Bazarov contesta con desdén: «El arte de hacer dinero, sí. ¡Y basta de hemorroides!». Por lo tanto, insiste Pavel Petrovič, el joven «es decir, ¿sólo cree en la ciencia?»; «Ya le dije anteriormente que no creo en nada. ¿Qué es la ciencia, hablando en términos generales? Hay ciencias como hay oficios, títulos pero la ciencia en general no existe en absolutoLe he dicho ya - replica Bazarov - que no creo en nada; y ¿qué es la ciencia en general? Existen las ciencias como existen los oficios y los diversos grados en la sociedad; pero la ciencia en general no existe en absoluto» [I. Turguenev, Padres e hijos. Madrid: Alianza, 1971, p. 30].

12 Cfr. E. Kuhn, Friedrich Nietzsches Philosophie des europäischen Nihilismus, Berlin-New York: de Gruyter, 1992, pp. 33-37; cfr. Sobre esto también P. Stellino, op. cit., p. 92. Kuhn afirma que en la lectura de la novela de Turgenev Nietzsche pudo haber sido estimulado por la lectura de las Lettres à une inconnue de Prosper Mérimée, que él cita en Humano, demasiado humano, y en cuyo segundo volumen el autor aconseja a la desconocida la lectura de Padres e hijos. En el mismo periodo Nietzsche lee otra novela de Turgenev, Tierra virgen, que según Kuhn, habría inspirado las consideraciones sobre el nihilismo contenidas en el fragmento 4[108] del verano de 1880 que hemos examinado más arriba. 
Sin embargo, la misma Kuhn opina que el «creer en el no creer llevado hasta el martirio» es, en realidad, una cita casi literal de Paul Bourget ${ }^{13}$. En el capítulo dedicado a Baudelaire de sus Essais de psychologie contemporaine Bourget cita «la rage meurtrière des conspirateurs de Saint-Petersbourg» poniéndola, entre otras cosas, junto a la «misanthropie acharnée des romanciers naturalistes» ${ }^{14}$ - para añadir inmediatamente después:

Il semble que du sang à demi asiatique des Slaves monte à leur cerveau une vapeur de mort qui les précipite à la destruction, comme à une sorte d'orgie sacrée. Le plus illustre des écrivains russes disait devant moi, et à propos des nihilistes militants: "Ils ne croient à rien, mais ils ont besoin du martyre..."15

El ilustre escritor ruso al que alude Bourget es Turgenev. Es difícil, en efecto, no escuchar el eco de las palabras que Bourget le atribuye en este fragmento de la primavera de 1884: «Elogio de los nihilistas: iprefieren aniquilar y perecer!» $(25[281], \mathrm{KSA}, 11,83)$.

De la obra de Turgenev, por otro lado, Nietzsche había podido leer un informe en los sucesivos Nouveaux essais de psychologie contemporaine del mismo Bourget. En este libro, objeto de una profunda lectura por parte de Nietzsche - sobre todo el capítulo sobre Turgenev, en el que se encuentran numerosos subrayados a lápiz ${ }^{16}$ - el autor inscribe a Turgenev en la categoría

13 Cfr. E. Kuhn, ibid, p. 244 y 244 nota 902; cfr. también P. Stellino, op. cit., p. 90.

14 P. Bourget, Essais de psychologie contemporaine, Lemerre, Paris 1883, p. 15. En el aforismo 347 de La gaya ciencia cita, antes de «nihilismo según el modelo de San Petersburgo», las «sectarias confesiones estéticas del tipo del naturalisme parisino» ( $F W, \mathrm{KSA}, 3,582$; OC III 863): una probable referencia a Émile Zola.

15 P. Bourget, op. cit., p. 16.

16 Cfr. G. Campioni-P. D'Iorio-M.C. Fornari-F. Fronterotta-A. Orsucci (eds.) (unter Mitarbeit von R. Müller-Buck), Nietzsches persönliche Bibliothek, Berlin-New York: De Gruyter, 2003, pp. 148-149. Otra fuente esencial de la que Nietzsche saca sus informaciones sobre el nihilismo ruso fue, como se sabe, el libro de Ferdinand Brunetière, Le roman naturaliste (Paris: Calman Lévy, 1883), que contenía un capítulo dedicado a Le roman du nihilisme (ibid, pp. 29-50), eliminado luego por el autor a partir de la edición de 1896. En el centro del análisis de Brunetière estaba la novela de Nikolaj Gavrilovič Černyševskij, ¿Qué hacer? (1863) que, aunque de pasada, el autor compara con Padres e hijos, juzgando que Černyševskij hubiese entendido «rétablir la sincérité d'un portrait» frente a las «caricature calomnieuse» del nihilista que Turgenev «avait dessinée dans le personnage de son Basarof» (ibid,pp. 31-32). El ejemplar del libro de Brunetière incluye las huellas de una lectura profunda por parte de Nietzsche (cfr. G. Campioni-P. D’Iorio-M.C. Fornari-F. Fronterotta-A. Orsucci, op. cit., pp. 157-158). Según Montinari, fue sobre todo gracias a este libro que Nietzsche «adquirió una preparación concreta sobre el nihilismo ruso» (M. Montinari, Compiti della ricerca nietzscheana oggi: il confronto di Nietzsche con la letteratura francese del XIX secolo, en G. Campioni-A. Venturelli [eds], La 'biblioteca ideale' di Nietzsche, Napoli: Guida, 1992, p. 270). Sobre la importancia de este libro que, como observa todavía Montinari ( $\mathrm{ibid}$.), resulta exclusivamente de los subrayados y notas que se encuentran en la página del ejemplar que tiene Nietzsche, insiste también Giuliano Campioni, el cual señala cómo Nietzsche no había citado sin embargo nunca el nombre de Brunetière «dans ses 
del pesimismo, observando que las más importantes de sus novelas «se terminent sur une impression d'accablement» ${ }^{17}$. En él, sin embargo, el pesimismo de fondo estaría corregido por un efecto final de ternura.

Il est pessimiste et il est tendre. La vision de la fatale caducité de toute existence l'amène à plaindre comme des victimes les pauvres créatures auxquelles a été infligée la vie [...]. Tourguéniev arrive ainsi à produire sur son lecteur un effet d'attendrissement inexprimable ${ }^{18}$.

Según estas observaciones, que inducen a desvelar en el nihilismo un subfondo de humanitarismo - evidente, por otra parte, en las circunstancias de la muerte de Bazarov - no es de extrañar que Nietzsche se haya mostrado fuertemente crítico frente a Turgenev. Cuando de pronto se le revela la figura de Dostoevskij ${ }^{19}$, la de Turgenev pasa irremediablemente a un segundo plano. La lectura de Los Demonios, que probablemente la hizo hacia finales de 1887 en la traducción francesa titulada Les possédés ${ }^{20}$, se le ofrece como la oportunidad de ver desde una perspectiva diversa, y en cierto modo opuesta, la temática ya presente en Padres e hijos. El espejo de esta perspectiva puede ser retenido en un fragmento de noviembre de 1887 - marzo de 1888 en el que Nietzsche traduce en alemán algunos pasajes de Los Demonios. Hacia el final del fragmento, que reproduce algunos pasajes de un discurso que Pëtr Stepànovič Verchovenskij dirige a Stavrogin, Nietzsche sustituye el nombre de Karmazinov - el escritor que en la novela de Dostoevskij es la contrafigura de Turgenev - el nombre del mismo Turgenev: «¿Sabe usted que el siervo se respetaba a sí mismo más de lo que se respetaba Turgeniev?...Se [le] golpeaba,

écrits ni dans sa correspondance» (G. Campioni, Les lectures françaises de Nietzsche, París: PUF, 2001, p. 48). Sobre el argumento, ver también P. Stellino, op. cit., p. 92.

17 P. Bourget, Nouveaux essais de psychologie contemporaine, Paris: Lemerre, 1886, p. 233.

18 Ibid., pp. 236-237.

19 La primera noticia que tenemos de la lectura nietzscheana de Dostoevskij describe una auténtica descarga eléctrica. En una carta a Heinrich Köselitz del 13 de febrero de 1887 dice Nietzsche: «¿Conoce a Dostoievski? Fuera de Stendhal, nadie me ha dado tanto placer y sorprendido tanto: un psicólogo con el que "me entiendo"» (KSB, 8, 24; OC V 267). Y en una carta a Franz Overbeck del día 23 de febrero la sorpresas parece todavía más acentuadas: De Dostoievsky, hasta hace pocas semanas, no conocía ni siquiera el nombre — ¡yo, hombre inculto que no lee ningún Journal! Un movimiento casual en una librería puso ante mis ojos la obra L'esprit souterrain, que acababa de ser traducida al francés $[\ldots]$. El instinto de familiaridad (¿o cómo podría llamarlo?) habló de inmediato, mi alegría fue extraordinaria» El volumen leído por Nietzsche contenía en realidad dos relatos de Dostoevskij: La patrona (1847) y las Memorias del subsuelo propiamente dichas. De estas últimas observa que le parecen «un rasgo de genio de la psicología, una especie de burla de sí mismo del $\gamma \nu \omega \theta \imath \sigma \alpha \nu \tau o \nu$ ». KSB, 8, 27-28; CO V 270); cfr. Sobre esto J.B. Llinares, Nietzsche descubre a Dostoievski. Notas sobre la lectura nietzscheana de La patrona, en «Estudios Nietzsche», 9 (Nietzsche y la hermenéutica), 2009, pp. 67-90.

20 Cfr. P. Stellino, op. cit., p. 119. 
pero él seguía fiel a sus dioses - mientras que Turgeniev abandonó a los suyos...»(11[341], KSA, 13, 150; FP IV 463).

\section{III. ¿UNA DISCREPANCIA CRONOLÓGICA?}

Si el encuentro de Dostoevskij interviene, por tanto, en la modificación de la visión nietzscheana de Turgenev, se pude suponer que, considerando una fecha muy tardía de aquel encuentro, habría sido por el contrario la lectura de Turgenev - situada, como se ha visto, en la segunda mitad de los años 70 - la que determina la primera posición de Nietzsche sobre el nihilismo. La evidente intensificación de las reflexiones nietzscheanas en la última parte de su producción, y, en particular, después de la lectura de Dostoevskij, confirma, más bien que desmiente, una familiaridad con el argumento que debe ciertamente remontarse a los años precedentes ${ }^{21}$.

En este sentido, también la lectura de Bourget, que es ciertamente determinante para las últimas reflexiones de Nietzsche, no puede considerarse como una fuente exclusiva. No se trata tanto de poner en discusión la bien conocida afirmación de Charles Andler según el cual el uso, por parte de Nietzsche, de la palabra «nihilismo» no se remontaría a «une secte d'anarchistes russes» ni al hecho de «qu'un héros de Tourgéniev, Bazaroff [...] appelle nihilisme le sentiment de sa vie manqué et sa nostalgie des ténèbres» sino, más bien, «l'usage nietzschéen du mot vient des Essais de psychologie contemporaine de Paul Bourget»; cuanto, si acaso, de poner en relación esta lectura con el tema de Europa, específico del último Nietzsche. La reflexión sobre el nihilismo y sobre la décadence, como «une grand maladie européenne», está ciertamente en el centro de muchos aforismos del V libro de la Gaia ciencia, así como del casi contemporáneo «fragmento Lenzerheide» sobre El nihilismo europeo; y Andler tiene razón cuando sostiene que, gracias a la reflexión sobre estos temas, Nietzsche se reconoce de alguna manera a sí mismo: «En réfléchissant à 1'Europe, Nietzsche se reconnait. En réfléchissant à son propre mal, il reconnaît l'Europe» ${ }^{22}$.

Las fechas en que se publicaron los dos libros de Bourget leídos por Nietzsche - 1883 y 1886 - son posteriores a la lectura de Dostoevskij y después de la hipotética lectura de Turgenev. Además, las fuentes que hemos examinado hasta ahora nos remiten a un contexto literario y psicológico, al menos, político, pero todavía no al significado filosófico del nihilismo.

21 Cfr. ibid, p. 91s.

22 Ch. Andler, Nietzsche. Sa vie et sa pensée (1920-1931), París: Gallimard 1958, vol. III, p. 418. 


\section{GUTZKOW: UNA SÍNTESIS FILOSÓFICO-LITERARIA}

Una mediación, en este sentido, podría estar determinada por un relato de Karl Ferdinand Gutzkow publicado en 1845 bajo el título Die Nihilisten. Gutzkow fue un escritor con cierto éxito, sobre todo como dramaturgo, además de ensayista y periodista. Había seguido las clases de Schleiermacher y Hegel, había participado en los movimientos revolucionarios de 1848 y fue miembro del movimiento literario de tendencia revolucionaria y progresista, Junges Deutschland, en el que también había participado Heinrich Heine, autor como ya se sabe muy querido por Nietzsche. Gutzkow pone de relieve a través de los protagonistas nihilistas del relato, con una vena fuertemente crítica, la desilusión de la clase burguesa después del fracaso de la revolución del 48. Como se ha observado: «el concepto de nihilismo, a menudo citado en el relato, tiene, sin duda, antes que Nietzsche, su significado moderno. Los nihilistas de Gutzkow rechazan toda verdad» ${ }^{23}$. El contexto social al que pertenecen los protagonistas es similar, como se ve, al de Padres e hijos. No es quizás arriesgado suponer que el relato de Gutzkow hubiese sido al menos conocido, sino incluso leído, por Turgenev ${ }^{24}$, que había estado en Berlín entre el 1833 y el 1841; allí había conocido, entre otros, a Herzen y Bakunin y había padecido la influencia de la filosofía de Hegel, manteniendo luego vivos los contactos con el ambiente alemán, también después de su retorno a Rusia.

Hay que subrayar, respecto a estos acontecimientos, la importancia del análisis de Dieter Arendt, según el cual podría deberse al relato de Gutzkow el giro en sentido político del concepto de nihilismo. De término «ante todo crítico-autocrítico se convierte, por decirlo así, en formula de exorcismo, y en una palabra agresiva injuriosa. Pero se anuncia lentamente la exigencia de una posible justificación de la negación». A esta exigencia responde el relato de Gutzkow, en el cual es «por primera vez perceptible una transvaloración» ${ }^{25}$ del significado del término. Es ahí donde «la profesión de fe en la nada como negación determinada adquiere un decisivo acento político». Arendt pone a Die Nihilisten, por un lado, junto al Lenz de Büchner - aunque advirtiendo que el relato se aleja mucho de él en cuanto al valor literario - y, por otro lado, junto a aquella concreción y radicalización del «concepto hegeliano de la negación entendida como Aufhebung dialéctica» llevada a cabo por Max Stirner. Gracias al trabajo desarrollado por la izquierda hegeliana, «el concepto de la negación se convierte finalmente en principio político de la revolución».

23 R. Duhamel, Die Decke auf den Kopf: Versuch einer Deutung des Nihilismus, Würzburg: Königshausen \& Neuman 2006, pp. 67-68.

24 Cfr., en este sentido, F. Volpi, Il nichilismo, Roma-Bari: Laterza 1996, p. 11.

25 D. Arendt, Der 'poetische Nihilismus' in der Romantik. Studien zum Verhältnis von Dichtung und Wirklichkeit in der Frühromantik, Tübingen: Niemeyer 1972, vol. II, p. 542. 
De este modo, observa todavía Arendt, «el nihilismo pasivo se convierte en un nihilismo activo individualista o anárquico» ${ }^{26}$.

Turgenev juega, por tanto, en este contexto, un papel decisivo en cuanto que gracias, entre otras cosas, a su conocimiento directo de Bakunin, modela la figura del anarquista nihilista: aquel Bazarov que «ha quizá permitido el modelo para el nihilismo confesional y activo de Nietzsche» ${ }^{27}$. Sin embargo, como se ha visto, detrás de él es el relato de Butzkow el que representa el auténtico parteaguas después del cual el nihilismo llega a tomar, antes que nada, una dirección política.

\section{MÁS ALlÁ de GUTZKOW, «FiLÓSOFO FRACASADO»}

Sin embargo, como hemos visto ya, Nietzsche se interesa de hecho poco por el nihilismo específicamente político. Y, además, no está documentado que leyese el relato de Gutzkow. Por otra parte, es cierto que conocía al escritor; su nombre aparece incluso en fragmentos relativamente tempranos que datan entre 1870 y 1872 . En el primer fragmento en el que aparece el nombre de Gutzkow se introduce un juicio sobre él en relación a algo que tiene un cierto interés del que dice anteriormente: «La novelística alemana moderna como fruto del hegelianismo: lo primero es la idea, que ahora es ejemplificada artificialmente»; siguiendo un juicio fulminante: "Gutzkow, como filósofo fracasado, es el transformed disformed, en general una caricatura de la relación schilleriana entre filosofía y poesía» (7[114], KSA, 7, 164; FP I 173). En un fragmento un poco posterior el juicio negativo se extiende a todo el movimiento del Junges Deutschland: "Gutzkow, alumno de Instituto de bachillerato degenerado. La Joven Germania como asociación de estudiantes que han abandonado los estudios» (8[113], KSA, 7, 266; FP I 241). Este fragmento pertenece a los materiales reelaborados después en las cinco conferencias Sobre el porvenir de nuestras escuelas, en las que se lee un nuevo juicio muy crítico sobre el valor poético de Berthold Auerbach y de Gutzkow: «semejante cuestión quedará zanjada inmediatamente cuando el disgusto no nos permita seguir leyendo ni a uno ni al otro» (BA, KSA, 1, 684; OC I 506). Mientras en la quinta conferencia se reitera el juicio sobre «como viva imagen del bachiller moderno ya convertido en literato» y como «hombre de cultura degenerado» (BA, KSA, 1, 746; OC I 539).

Como se ve, se trata de juicios genéricos que hunden sus propias motivaciones en la crítica de la cultura alemana que será el tema sobre todo de

26 D. Arendt, Einleitung, in D. Arendt (ed.), Nihilismus. Die Anfänge von Jacobi bis Nietzsche, Köln: Hegner 1970, pp. 70-71.

27 Ibid., p. 75. 
la I y de la II Consideraciones intempestivas. En el Nachlass no se encuentran, sin embargo, referencias directas a cada una de las obras de Gutzkow ni, mucho menos, al escrito de Die Nihilisten. A pesar de esto, se leen en aquel relato descripciones de la actitud del nihilista que, de un modo u otro, deben haber proporcionado la inspiración a las reflexiones de Nietzsche. Esto puede haber sucedido o bien indirectamente, por el gran existo del relato, o bien porque las ideas expuestas en él plásticamente estaban ya presentes en el debate cultural de la época.

Jean Reps, uno de los personajes del relato, habla de un «espíritu de la desesperación» que se produce «después de la reacción que he visto llegar francamente con terror». Con referencia a los motivos revolucionarios él declara que «el espíritu del siglo ha hablado a los hombres en todas las lenguas posibles»; pero, añade, «eso no me ha llamado a las barricadas» ${ }^{28}$. La desesperación designa el estado de ánimo de una clase burguesa que permanece en la indecisión: no suficientemente comprometida con la revolución por un lado y, por el otro, desilusionada en cualquier caso por la falta de afirmación de la revolución misma. Un poco más adelante otro personaje, Eberhard Ott, describe críticamente la actitud nihilista con expresiones que recuerdan a la posición de la generación de los «padres» en la novela de Turgenev. Hay que destacar en sus palabras, la referencia al origen teológico del concepto de nada y la desvalorización que éste padece en la práctica de los nihilistas:

Se considera la creación a partir de la nada un milagro que supera nuestra imaginación y la capacidad de creer. Pero cuán formativo sea la nada lo enseña la experiencia de cada día. La negación a cualquier precio (die Negation um jeden Preis $)[\ldots]$ se eleva ahora por todas las partes de sus ruinas, de sus cementerios, de sus jardines llenos de malas hierbas.

Ott estaría dispuesto a creer que esa negación es el fruto de una «transformación espiritual interior» no fuese que, a esta última, debería pertenecer «la religión, la intimidad con Dios, la iluminación interior». Aquello que por el contrario mueve a los nihilistas es, en última instancia, la «postración»(Erschöpfung); ellos

odian nuestros impulsos. Odian el negro, el blanco, encuentran que siempre, de Aquel que pretende nuestro amor y nuestro fervor, solo lo opuesto está justificado. El lobo enturbia el agua al cordero porque está saciado. Nada, por lo tanto, está para ellos demostrado, nada es sólido. 
Los nihilistas sostienen «que toda esperanza y todo sueño, todo querer y toda voluntad son superfluos» ${ }^{29}$.

En resumen, los nihilistas son llamados ateos, respecto a la religión, y como escépticos respecto a la filosofía ${ }^{30}$.

\section{NiHILISMO Y ESCEPTICISMO}

Nietzsche es muy consciente de la estrecha relación entre escepticismo y nihilismo. Valgan, para todos los ejemplos posibles, las palabras del «fragmento Lenzerheide» sobre El nihilismo europeo, que mencionan también la extracción burguesa de los nihilistas: «Un cierto cansancio espiritual, que la larga lucha de opiniones filosóficas (philosophischer Meinungen) ha llevado hasta un desesperanzado escepticismo frente a la filosofía, caracteriza también a la clase, de ninguna manera baja, de estos nihilistas» (5[71]. 13, KSA, 12, 216; FP IV 13. 167). Mientras que en un fragmento un poco posterior (otoño 1887), se dice muy claramente lo que significa Negation um jeden Preis: «Un nihilista es el hombre que, respecto del mundo tal como es, juzga que no debería ser, y respecto del mundo tal como debería ser, juzga que no existe»; nace, de este modo, «el pathos del "en vano" (das Pathos des "Umsonst"): un sentimiento según el cual «existir (actuar, sufrir, querer, sentir) no tiene sentido» (9[60], KSA, 12, 366; FP IV 250).

Que el escepticismo, y a través de él el nihilismo, pueda ser generado por el conflicto de las doctrinas filosóficas - reducidas, como se ha visto, al rango de simples Meinungen - inscribe la posición de Nietzsche en un escepticismo cuyas conclusiones él sacará solo más tarde ${ }^{31}$, pero cuyas raíces pueden ser individuadas ya en el primer prólogo al escrito no publicado La filosofía en la época trágica de los griegos, en la que él advierte que «los sistemas filosóficos solo son completamente verdaderos para sus fundadores», mientras que «para todos los filósofos posteriores, ordinariamente, cada uno de estos sistemas suele ser un gran error, para las mentes menos perspicaces una suma de errores y verdades». Solo quien está en condiciones de «disfrutar de los grandes

29 Ibid, pp. 119-120.

30 Cfr. F. Vercellone, Il nichilismo, Roma-Bari: Laterza 1992, pp. 24-25, para quien estas actitudes en la forma de pensar son comunes a todos los autores del Junges Deutschland y son reconducibles a una reacción al idealismo: «Al Dios que para el idealismo era un puro ens intelectual, lo sustituye ahora el panorama de una naturaleza sustancialmente amoral, que prescinde de Dios, y da lugar a una realidad completamente comprometida en su devenir y en sus leyes».

31 Jessica N. Berry señala, por ejemplo, lo que Nietzsche afirma en el aforismo 110 (Origen del conocimiento), en el que el origen de «esa probidad y escepticismo más sutil» es individuada «donde dos proposiciones opuestas parecían aplicables a la vida» ( $F W$, KSA, 3, 470; OC III 796). Berry observa esto: «parece una indicación tan clara que creeríamos que tiene en mente a los pirronistas» (J.N. Berry, Nietzsche and the Ancient Skeptical Tradition, New York: Oxford University Press 2017, p. 29). 
hombres» podrá «disfrutar de tales sistemas, aunque sean completamente erróneos»».

Lo que en ellos es algo completamente irrefutables es un «talante y un colorido personales», de manera que se podrá servir de ellos «para obtener la imagen del filósofo: de la misma manera que podemos deducir de la vegetación de un lugar la naturaleza del terreno» ( $P H G, \mathrm{KSA}, 1,801$; OC I 571).

Aunque el escrito no contenga naturalmente ninguna referencia a Pirro de Elide, que no pertenece a la época que Nietzsche somete a examen, tal visión, que puede definirse con todo derecho escéptica, remite sin embargo al uso pirroniano de las épocas, de las que Nietzsche tiene noticia, al menos, de Diógenes Laercio, al que había dedicado sus primeros estudios como filólogo ${ }^{32}$. Pirro, por el contrario, entra en juego directamente en el aforismo 213 (El fanático de la desconfianza y su fianza) de El viajero y su sombra: un diálogo que Nietzsche construye sobre el modelo de los Dialogues des morts de Bernard de Fontenelle (citado, de hecho, en el aforismo inmediatamente posterior) y, a través de él, sobre el de los Dialoghi dei morti de Luciano di Samosata ${ }^{33}$. El nombre de Pirrón aparece con una cierta insistencia en los fragmentos de la primavera de 1888, después de la lectura, por parte de Nietzsche, del libro de Victor Brochard, Les sceptiques grecs, publicado en $1887^{34}$; en un periodo, sin embargo, como hemos ya observado, en el que

32 Se trata de De Laertii Diogenis fontibus (publicado originariamente en el «Rheinisches Museum» en dos partes respectivamente, en 1868 y 1869); Beiträge zur Quellenkunde und Kritik des Laertius Diogenes (publicado originariamente en las ediciones del Pädagogium de Basilea en 1870), ahora en KGW, II/1, respectivamente 75-167, 169-190 y 191-245. Para los estudios de Nietzsche sobre Diógenes Laercio cfr. M. Gigante, Friedrich Nietzsche nella storia della filologia classica, en «Rendiconti dell'Accademia di Archeologia Lettere e Belle Arti di Napoli», vol. LIX, 1984, pp. 18ss.; J. Barnes, Nietzsche and Diogenes Laertius, en «Nietzsche-Studien», vol. 15, 1986, pp. 16-40. Refiriéndose al discípulo de Pirrón, Timón de Fliunte, Diogenes Laercio afirma que la sentencia «"A toda proposición se contrapone otra” comporta la suspensión del juicio» (IX, 76). Mientras que la referencia de Nietzsche a elemento «personal» podría haberse inspirado en la afirmación de otro discípulo de Pirro, Enesidemo, el cual, según Diógenes, sostiene que Pirrón «aplicaba en la filosofía el principio de la suspensión del juicio», pero «en la vida cotidiana se comportaba con cautela y clarividencia» (IX, 62). Berry da por sentado que Nietzsche puede haber tomado sus primeros conocimientos de Pirro de Diógenes Laercio, desde el momento en que él «trabaja arduamente, sobretodo en el libro noveno, algunas de las secciones más largas que se dedican a considerar las vidas de Pirrón de Elis [...] y de sus seguidores más inmediatos, como Timon de Fliunte» (J.N. Berry, op. cit, p. 26).

33 Cfr. WS, KSA, 2, 645-646; OC III 432). Sobre un posible anuncio en este aforismo sobre lo que Nietzsche designará después con el término gaya ciencia, cfr. A.Chr. Bertino, Nietzsche und die hellenistische Philosophie. Der Übermensch und der Weise, en «Nietzsche-Studien», vol. 36, 2007, pp. 127-128; remito sobre ello también a mi Introduzione a Nietzsche, Bologna: Il Mulino 2017, pp. 118-119; se vean, además, M. Brusotti, Die Leidenschaft der Erkenntnis. Philosophie und ästhetische Lebensgestaltung bei Nietzsche von "Morgenröthe» bis "Also sprach Zarathustra», Berlin-New York: De Gruyter1997, p. 631 y C. Zittel, Der Dialog als philosophischer Form bei Nietzsche, en «Nietzsche-Studien», vol. 45, 2016, p. 103.

34 Cfr. J.N. Berry, op. cit., p. 28, según la cual después de la lectura del libro de Brochard es 
Nietzsche reflexiona intensamente sobre el concepto de nihilismo. No es por tanto raro que en dos fragmentos de aquel periodo él defina a Pirrón como un «nihilista» 35 .

\section{EL NIHILISMO Y LA NADA}

Si con esta definición se ha cerrado el círculo entre escepticismo y nihilismo, todavía no podemos sin embargo considerar que hemos llegado al origen de la cuestión. En el último periodo de su reflexión Nietzsche parece recurrir al concepto de nihilismo para aclarar el de escepticismo, más bien que al contrario. Para ir más allá deberemos considerar el nihilismo en su concepción esencial, es decir, como reflexión sobre la «nada». Si el término «nihilismo» aparece por primera vez de una manera fugaz en una carta a Köselitz del 13 de marzo de $1881^{36}$, para después recuperarlo de una manera fugaz en un fragmento del verano-otoño de $1882^{37}$, sin embargo comienza a aparecer insistentemente solo a partir de 1885, y el término «nihilista» aparece por primera vez en un fragmento de $1880^{38}$, pero tiene un uso recurrente solo a partir de 1884; la reflexión sobre la nada reviste por el contrario un papel de primer orden en el aforismo 125 (El hombre loco) de La gaya ciencia. Después de haber anunciado la muerte de Dios - «“A dónde ha ido Dios?”,

cuando «el entusiasmo de Nietzsche por las variedades antiguas de escepticismo» se hace más evidente: «los apuntes de los fragmentos póstumos de Nietzsche desde la primavera de 1888 en adelante indican que adquirió el libro casi inmediatamente después de su publicación y lo leyó con mucho interés». El ejemplar del libro de Brochard leído por Nietzsche se conserva en su biblioteca: cfr. G. Campioni-P. D’Iorio-M.C. Fornari-F. Fronterotta-A. Orsucci, op. cit., p. 154.

35 Cfr. 14[99], KSA, 13, 277 (FP IV 545): «Pirro, al igual que Epicuro, dos formas de la décadence griega [...] Epicuro más ingenuo, más idílico, más agradecido; Pirro, más viajado, con más experiencias vividas, más nihilista...»; y 14[100], KSA, 13, 278 /FP IV546): en la filosofía posterior a Sócrates existía «una única figura original: un epígono, pero necesariamente el último...el nihilista Pirro [...]. Pirro, pasando por encima de Protágoras, se remonta a Demócrito» La designación de Pirro como nihilista quizás le fue sugerida a Nietzsche por algunas expresiones que él leyó en el libro de Brochard: «Pyrrhon n'attend rien, n'espère rien, ne croit à rien: pourtant il vit comme ceux qui croient et espèrent. Il n'est soutenu par rien et il se tient debout» (V. Brochard, Les sceptiques grecs, Imprimerie Nationale, Paris 1887, p. 73); y aún más: de su predecesor Anassarco de Abdera Pirro «avait appris que toutes les opinions sont relatives, et que l'esprit humain n'est pas fait pour la verité absolue» (ibid., p. 74).

36 «Necesito todo tipo de salud - ¡me ha calado tan hondo en el corazón ese "nihilismo descorazonador"! (dieser "herzbrecherische Nihilismus") ¡Pues bien, sigamos de buen ánimo!» (KSB, 6, 68; CO IV 108). Nietzsche responde a una carta de Köselitz que hacía referencia a cómo Édouard Schuré había definido su pensamiento como un «nihilisme écouré».

37 Cfr. 2[4]: «LOS AMIGOS DE LA VIDA/ El nihilismo como pequeño preludio. / Imposibilidad de la filosofía» (KSA, 10, 43-44; FP III 49).

38 Cfr. 4[103]: «El consuelo de Lutero cuando la cosa no iba adelante, "el fin del mundo". Los nihilistas tenían a Schopenhauer de filósofo. Todos o los que son extremadamente activos, cuando se dan cuenta de que sus deseos son imposibles [de realizar], desean que el mundo se deshaga en pedazos (Wotan)». (KSA, 9, 125; FP III 563). 
exclamó, “¡yo os lo diré!” ¡Nosotros lo hemos matado, vosotros y yo! ¡Todos nosotros somos sus asesinos!"» - el hombre loco se pregunta cómo ha sido posible cometer tal asesinato y se pregunta, entre otras cosas: "¿No erramos como a través de una nada infinita?"». Esta pregunta está en el centro de otra serie que describe con precisión el desconcierto en el que la condición humana se precipita después de la muerte de Dios:

Cómo hemos sido capaces de beber todo el mar? ¿Quién nos dio la esponja para borrar todo el horizonte? ¿Qué hemos hecho al desprender la tierra de su sol? ¿Hacia dónde se mueve ahora? ¿Hacia dónde nos movemos nosotros? ¿Lejos de todos los soles? ¿No nos precipitamos permanentemente? ¿Y también hacia atrás, hacia adelante, hacia todos los lados? ¿Hay aún un arriba y un abajo?

Y continúa: «¿No sentimos el hálito del espacio vacío? ¿No hace más frío? ¿No viene continuamente la noche y más noche? ¿No es necesario encender linternas por la mañana?» ( $F W, \mathrm{KSA}, 3,480-481$; OC III 802). Estas preguntas, destinadas a quedar sin respuesta, surgen de la conciencia adquirida de la pérdida de centralidad de la condición humana después de la revolución copernicana: más evidente, aunque no explícitamente nombrada, en las referencias físico-astronómicas. Que esta condición pueda ser definida «nihilista» lo testimonia un fragmento de 1885-1886: «Las consecuencias nihilistas de la actual ciencia de la naturaleza [...] De su actividad se sigue finalmente una autodestrucción, un dirigirse en contra de sí, una anticientificidad. - Desde Copérnico, el hombre se desliza desde el centro hacia la x». (2[127]. 5, KSA, 12, 126-127; FP IV 115) ${ }^{39}$. La referencia a Copérnico se retoma en el parágrafo $\S 25$ de la tercera disertación de La Genealogía de la moral, en la que la connotación nihilista es explicitada con una llamada al tema de la nada: «Desde Copérnico parece estar el hombre sobre un plano inclinado, - rodando cada vez más rápido y cada vez más lejos del punto central - ¿hacia dónde?, ¿hacia la nada?, ¿al "sentimiento, que le hiende, de ser nada"?» (GM, KSA, 5, 404; OC IV 555). Ambos textos pueden sin duda ser considerados como un desarrollo del tema propuesto en los pasajes de $L a$ gaya ciencia.

Tras las referencias de carácter físico-astronómico, sin embargo, se abre otro contexto que remite, por decirlo así, a un ámbito teológico. No se trata solamente del tema de la muerte de $\operatorname{Dios}^{40}$, algo por sí descontado, sino de los

39 Hay que subrayar que el fragmento comienza con una frase bien conocida que los editores pusieron al principio del primer libro de la antología póstuma La Voluntd de Poder: "El nihilismo está a las puertas: ¿de dónde nos llega éste, el más inquietante de todos los huépedes?» (2[127], KSA, 12, 125; FP IV 114).

40 He tratado de demostrar cómo el tema de la «muerte de Dios» procede de un contexto muy presente en la teología luterana en mi Introduzione a Nietzsche, op. cit., pp. 148 ss. y 167 nota 3. 
nexos problemáticos que se conectan con el significado de la linterna. Que se deban «encender linternas» cuando es de día es una obvia necesidad dictada por el apagarse de la luz de Dios después de la proclamación de su muerte. Obvio es también la referencia a la figura de Diógenes de Sinope (el cínico) así como la tradición lo ha transmitido ${ }^{41}$. La transferencia de esta caracterización al tema de la muerte de Dios implica, sin embargo, una transvaloración de su significado en relación a la condición del hombre moderno. Un aforismo de El viajero y su sombra, con el título significativo El Diógenes moderno, dice: "Antes de buscar al hombre, habría que haber encontrado la linterna. — ¿Tendrá que ser la linterna del cínico?»(WS, KSA, 2, 553; OC III 380). Esta linterna es el primer polo de una relación de significado que tiene, en el otro polo, la linterna del hombre loco, cuyo sentido podemos definir con razón como «nihilista»: frente a la reacción sorprendida de la multitud a quien ha dirigido sus preguntas, el hombre loco «lanzó al suelo su linterna, que saltó en pedazos y se apagó» ( $F W, \mathrm{KSA}, 3,481$; OC III 803). Es esencial recordar que la multitud en cuestión, a quien se anuncia la muerte de Dios, no es una multitud de creyentes, sino de no creyentes: «estaban allí reunidos muchos de los que no creían en Dios», así «gritaban y reían todos a la vez» (Ibid.). El Dios del que se habla es aquel cuya muerte ha sido ya proclamada en el aforismo 108 (Nuevas batallas) y cuya sombra, como la de Buda, se proyecta sobre las paredes de una cueva: «Dios ha muerto: pero tal como es el modo de ser de los hombres, quizás seguirá habiendo durante siglos cavernas en las que se muestre su sombra» ( $F W$, KSA, 3, 467; OC III 794). Puesto que la caverna es, en una alusión evidente al mito platónico, la caverna del conocimiento, el aforismo está en clara relación con el aforismo 539 (¿Acaso sabéis lo que queréis?) de Aurora: «¿No teméis reencontrar en la gruta de cada conocimiento vuestro propio fantasma, sudario con que se disfraza la verdad para vosotros?» $(M, \mathrm{KSA}, 3,308$; OC III 680). Teniendo en cuenta este aforismo, el inciso del precedente - so wie die Art der Menschen ist - indica con claridad que la sombra de Dios es una proyección del hombre mismo. Esto es aquello que la linterna del Diógenes moderno habría debido de ser capaz de ver; pero el gesto de decepción nihilista con el que el hombre loco, una contrafigura deforme del Diógenes moderno, arroja y destruye la linterna, indica que la kenosis de Dios en el hombre no puede suceder sin que se deba descontar la pérdida y el luto que un tal evento comporta. A Nietzsche no le basta con que el hombre se reapropie de la propia forma alienada en Dios, como él había aprendido de su lectura juvenil de Feuerbach ${ }^{42}$. En la sombra

41 Cfr. Diógenes Laerzio, VI, 41: «Durante el día [Diógenes] iba con la linterna encendida, diciendo: "busco al hombre"».

42 El 27 de abril de 1862, mientras Nietzsche era todavía estudiante en Pforta, escribe para la asociación «Germania», fundada por él junto a los amigos Wilhelm Pinder y Gustav Krug el 15 
de la dialéctica se esconde el desconcierto nihilista. También cuando en el af. 343 (Lo que significa nuestra alegría), que abre el V libro de La gaya ciencia, el acontecimiento de la muerte de Dios aparecerá «como una nueva especie, [...] de luz, de felicidad, alivio, alegría, coraje, aurora», esto sucederá solamente porque «estamos quizás bajo las consecuencias inmediatas de ese acontecimiento», y todavía no sabemos «qué ha ocurrido propiamente con él»: la «larga profusión y sucesión de derribo, destrucción, hundimiento, derrumbe que nos espera». Por lo tanto, si «finalmente el horizonte nos parece de nuevo libre», debemos sin embargo admitir que incluso «no sea claro». En el conceder que «el acontecimiento mismo es demasiado grande, demasiado lejano, demasiado apartado de la capacidad de comprensión de muchos» (FW, KSA, 3, 573-574; OC III 858) resuena todavía el doloroso interrogatorio del hombre loco « ¿No es la grandeza de este acto demasiado grande para nosotros? ¿No tenemos que volvernos nosotros mismos dioses para ser siquiera dignos de él?» ( $F W, \mathrm{KSA}, 3,481$; OC III 803). Esta pregunta revela su trampa si se pone en relación con el eritis sicut dii que la serpiente promete a los hombres si comen del fruto del conocimiento $(\mathrm{Gn} 3,5)$. Pero todos los interrogantes del hombre loco remiten a la condición humana tal y como se representa en el Antiguo Testamento. Según la convincente hipótesis formulada por Hans R. Jauss, las preguntas del hombre loco remiten a la serie de setenta contrapreguntas con las que Yahvé replica a las preguntas con las que Job lamenta su obstinado silencio frente a los sufrimientos infligidos a él. El sentido de aquellas contrapreguntas y el «argumento destructivo» que Jauss resume así: «¿Eres tu quizás el Creador, para osar interrogarme de esta manera? $\rangle^{43}$. Particularmente es más precisa la correspondencia entre las preguntas del hombre loco sobre el orden cósmico - respecto al «mar, el horizonte, el cielo y la tierra» - y las contrapreguntas de Jahvé a Job ${ }^{44}$, ambas

de julio de 1860, un artículo con el título: Libertad de la voluntad y fatum (KGW, I/2, 437-440). El escrito es retomado parcialmente por Nietzsche en una carta a Pinder en la que añade estas palabras como conclusión: «El hecho de que Dios se haya convertido en hombre no hace más que recordarnos que el hombre no debe buscar su beatitud en el infinito, sino que debe fundar sobre sobre la tierra su paraíso; la ilusión de un mundo ultraterreno [...] era el producto de una edad infantil de los pueblos». El «misterio» del anuncio cristiano es «que Dios se ha hecho hombre. Entre difíciles dudas y luchas la humanidad consigue la mayoría de edad: reconoce en sí misma el comienzo, el medio y el fin de la religión». (KSB, 1, 202; CO I 212). La frase que Nietzsche pone entre comillas es una cita casi literal de La esencia del Cristianismo de Feuerbach.

43 H.R. Jauss, Ästhetische Erfahrung und literarische Hermeneutik, Frankfurt am Main: Suhrkamp $1984^{2}$, p. 451.

44 Cfr. ibid, p. 464. Sobre todo la pregunta del hombre loco: «¿Cómo hemos sido capaces de beber todo el mar?» Corresponde a Job 38, 8: «¿Quién cerró con puertas el mar [...]?»; mientras las preguntas siguientes sobre borrar el horizonte y sobre el destino de la tierra «liberada de la cadena de su sol» corresponde a Job 38, 12: «¿A caso has mandado tú en tu vida a la mañana/ ya has enseñado 
series se recogen en torno a un significado análogo: «En Job la imposibilidad de responder a las contrapreguntas demuestra la impotencia del hombre para comprender la obra del poietes divino: En Nietzsche debe demostrar cómo matar a Dios es algo inimaginable» ${ }^{45}$. Puesto que, sin embargo, aquella acción es «paradójicamente»y «realmente acontecida», esto significa que aquel cosmos, del que las razones inescrutables de su orden Yahvé reivindica para sí mismo, excluyendo que otros pudiesen compartir la responsabilidad, es ahora abandonado a sí mismo, al caos, y se vuelve de repente vacío. De ahí la invocación de Job: «¡Quién me diera que se me escuchase! / ¡Ahí va mi firma! ¡Respóndame el Todopoderoso!» (Job, 31, 35) - está destinada, esta vez, a quedar sin respuesta. El orden eventualmente presente en cada una de sus regiones no remite a un orden superior que lo rija. Como escribe en el aforismo 109 (¡Guardémonos!) de La gaya ciencia, «el orden astral en el que vivimos es una excepción» $\mathrm{y}$, si eso ha hecho posible «la formación de lo orgánico», esta no es más que «la excepción de las excepciones». Solamente nuestras «humanizaciones estéticas» (ästhetische Menschlichkeiten) podrían lamentar aquella «falta de orden, articulaciones, forma, belleza, sabiduría» que es, por el contrario, la regla de las «jugadas fallidas» de la mano divina ${ }^{46}$. Finalmente hay que guardarse «de decir que en la naturaleza existen leyes. Existe solo la necesidad». Cada forma y persistencia que quisiésemos individuar en un cosmos que es «caos hasta el final de los tiempos», comprendida la materia «un error del mismo tipo que el dios de los eléatas» - no es más que una de las tantas «sombras de Dios» de las que hay que liberarse ( $F W$, KSA, 3, 468-469; OC III 794).

Más allá de la radicalización de las expresiones, con esto Nietzsche no va mucho más allá de la drástica separación entre naturaleza y mundo humano

su lugar a la aurora/ para que ocupe los extremos de la tierra [...]?» y a Job 38,33 «¿Has enseñado tú a los cielos su ley/ y determinado su influjo sobre la tierra?».

45 Las conclusiones que extrae Jauss son muy interesantes: el hecho de que Dios haya muerto «implica inevitablemente que antes no podía estar muerto - una prueba ex negativo de la existencia de Dios, que coloca al nihilismo de Nietzsche en una posición singularmente ambigua» (ibid., pp. 465). Partiendo de una constatación análoga, Hans Blumenberg interpreta el carácter problemático de la muerte de Dios como un argumento que Nietzsche usa contra "el ateísmo vulgar» que mera y simplemente niega la existencia de Dios: «Su "Dios muerto" es un Dios que se ha convertido en definitivo con la muerte, cuya existencia en la perfección no alcanza ninguna negación» (H. Blumenberg, Matthäuspassion, Frankfurt am Main: Suhrkamp 1988, p. 302).

46 Se trata de la tirada de dados. Pocas líneas después sobre la posibilidad de que «fallen» (verunglückten), Nietzsche precisa: «También la expresión "jugada fallida” es ya una antropomorfización que encierra en sí una crítica. ¡Pero cómo tendríamos derecho de criticar o alabar al todo!» ( $F W$, KSA, 3, 468; OC III 794). No hay duda de quien lanza los dados es la mano de Dios; cfr. Za, KSA, 4, 289; OC IV 216): «Pues la tierra es una mesa divina, temblorosa de nuevas palabras creadoras y de dados divinos»; donde es evidente el paralelismo entre la creación divina que hace que las cosas sean innombrables, como se describe en el Génesis, y la casualidad de la jugada de dados. 
indicada por Kant en la celebérrima página que cierra la Crítica de la razón práctica $^{47}$.

Privado del sentido que viene del ser conocido como creación divina, el universo recae en aquella nada de la que se pretende que haya tenido origen.

\section{NiHILISMO Y MEDIOEVO}

Como se recordará, uno de los personajes del relato de Gutzkow toma del misterio divino de la creatio ex nihilo el origen remoto del nihilismo. En cuanto esta sugerencia pueda parecer fugaz y colocada en un contexto, en su conjunto, heterogéneo, eso denuncia sin embargo un conocimiento de la antigüedad y la complejidad del tema. Wolfgang Müller-Lauter ha recordado cómo en la segunda mitad del siglo XII, el término «Nihilianismus» indicaba una dirección herética de la cristología, según la cual «el logos eterno no puede llegar a ser cualquier cosa, puesto que la naturaleza humana se adapta a Cristo solo accidentalmente. Este sería, en cuanto hombre 'non aliquid', es decir, un individuo ${ }^{48}$. Si el término nihilianismus es, con toda probabilidad, el predecesor más antiguo del término «nihilsmo», la reflexión sobre la nada se remonta todavía más atrás: precisamente al año 800 y a la Epistola de nihilo et tenebris di Fredegiso de Tours. Afirmando que la Iglesia nacía de Cristo tiene por cierto «divinam potentiam operatam esse ex nihilo terram, aquam, aera et ignem, lucem quoque et angelos, atque animam hominis», Fredegiso corrige en un punto esencial a Agustín, que escribe: «Tu enim Domine, fecisti mundum de materia informi, quam fecisti de nulla re pene nullam rem» (Conf. XII, 8). Mientras tanto Agustín pone entre lo increado, la nada absoluta, y el mundo la «casi nada» de la materia, Fredegiso hace derivar la creación directamente de la nada ${ }^{49}$. Mantiene de este modo la creación de la nada dentro de una «dimensión lógico-gramatical», en la que la nada es «vox significativa, sujeto de enunciación» ${ }^{50}$. De hecho, Fredegiso observaba: «Igitur nihil, si

47 «Dos cosas llenan el alma de admiración y veneración de una manera siempre nueva y creciente, cuanto más a menudo y durante más tiempo se ocupa la reflexión de ellas: el cielo estrellado por encima de mí y la ley moral en mì». Más allá de designar una posible afinidad entre los dos ámbitos, la frase subraya la recíproca inconmensurabilidad. Mientras que el primero está ligado a la naturaleza animal del hombre, en cuanto es «el espectáculo de una cantidad innumerable de mundos» que «anula de hecho mi importancia de creatura animal que debe devolver nuevamente al planeta la materia de donde salió», el segundo «por el contrario, eleva infinitamente mi valor como valor de una inteligencia, mediante mi personalidad en la cual la ley moral me revela una vida independiente de la animalidad y aun de todo el mundo sensible». ( $K d p V, \mathrm{~V}, 161-162)$.

48 W. Müller-Lauter, voz en «Nihilismus» en J. Ritter-K.Gründer (ed.), Historisches Wörterbuch der Philosophie, Basel: Schwabe 1984, vol. 6, col. 846.

49 Cfr. F. D’Agostini, Il nulla e la nascita filosofica dell'Europa, en «Consecutio Rerum», a. I, n. 2, pp. 19-20.

50 Ibid., p. 20. 
modo nomen est, ut grammatici asserunt, finitum nomen est»; y en cuanto tal no puede no ser cualquier cosa: «Nihil autem aliquid significat. Igitur nihil eius significatio est quid est». La Epistola de Fredegiso tiene una influencia decisiva sobre las filosofías inmediatamente posteriores, en particular sobre Anselmo de Aosta, cuya prueba ontolológica de la existencia de Dios muestra, en la estructura argumentativa una especie de paralelismo con la formulación fredegisiana ${ }^{51}$.

Dada la amplitud y la complejidad del problema, no podemos sacar de los argumentos tratados más que la conclusión de que el nihilismo, en cuanto reflexión filosófica sobre la nada, tiene una larga historia detrás de sí en el momento en el que llega a ser, al comienzo del siglo XIX, argumento corriente: como punto de partida para la literatura y como mensaje político. Aunque se toma como algo asumido que el término «nihilismo» entra en el debate filosófico con el uso que hace de él Friedrich Jacobi en la célebre carta abierta a Fichte $(1799)^{52}$, también eso se presenta implícitamente en el surco de la tradición mencionada ${ }^{53}$, dando pie en todo caso a una mediación decisiva sobre las sucesivas utilizaciones literarias y políticas posteriores.

\section{Hermann Reuter: UNA POSIBLE FUENTE DE NiETZSChE}

Para concluir, vayamos ahora a la cuestión que habíamos planteado desde el inicio: ¿al tratar su idea filosófica del nihilismo Nietzsche se remonta conscientemente a esta tradición, o bien la reinventa ex novo, partiendo de las sugerencias que le proporcionaba sobre todo la literatura, especialmente la rusa?

51 Cfr., Ibid., p. 13

52 Jacobi an Fichte, en F. Jacobi, Werke, Leipzig, Fleischer: Leipzig 1816 (reproducción reprográfica: Darmstadt: Wissenschaftliche Buchgesellschaft 1968), vol. III, p. 44: «Verdaderamente, querido amigo Fichte, no tiene que molestarme que usted y cualquier otro, quiera llamar quimerismo lo que yo contrapongo al idealismo, lo que yo llamo despectivamente nihilismo». La carta abierta es una abierta defensa de la propia «fe filosófica», en favor de una evidencia inmediata de Dios (de ahí que la califique de «quimerismo») y contra la disolución de su idea en los sistemas de las filosofías idealistas: de Fichte como de Schelliing. Como dice Arendt, con su polémica, Jacobi quiere desenmascarar el idealismo como «un pensamiento que gira en torno al sujeto, y al asentarse en la idealidad se queda privado de realidad objetiva de cualidad tanto física como metafísica y que tiene lugar en un ámbito de apariencia vacía, acósmico y privado de ser, y no es nada más que nada» (D. Arendt, Einleitung, en D. Arendt [ed.], Der Nihilismus als Phänomen der Geistesgehschichte in der wissenschaftlichen Diskussion unseres Jahrhunderts, Darmstadt: Wissenschaftliche Buchgesellschaft 1974, pp. 7-8). Véase también, en el mismo volumen, la contribución de Süß, Der Nihilismus bei F.H. Jacobi, ibid., pp. 65-78 (al principio en «Theologische Literaturzeitung», 76, 1951, coll. 193-200). Sobre Jacobi y el nihilismo cfr. también F. Vercellone, op. cit., pp. 3-8 y F. Volpi, op. cit., pp. 13-15.

53 Se pueden individualizar elementos de afinidad entre la disolución nihilista que el idealismo operaba, según Jacobi, frente a la evidencia divina y la demostración lógico-linguística de la existencia de Dios de los filósofos medievales. 
Si el origen de la reflexión sobre la nada, en cuanto antecedente del concepto filosófico del nihilismo, profundiza sus propias raíces en el Medievo, la respuesta debería ser favorable a la segunda opción, puesto que sabemos que, entre las muchas lagunas que la formación filosófica de Nietzsche denunciaba, la relativa a la filosofía medieval era quizás la más vistosa. Sin embargo sabemos también lo mucho que estuvo interesado e informado, también a causa de la amistad con Overbeck, sobre la teología de su tiempo. Entre las obras que él seguramente había leído estaba el libro del teólogo protestante Hermann Reuter, Geschichte der religiösen Aufklärung im Mittelalter, publicado en 1875. Que Nietzsche leyó el libro no solamente se deduce del hecho que tenía un ejemplar del libro, con signos de lectura, y que se conserva en su biblioteca ${ }^{54}$; sino además de la utilización tácita que hace de él en el aforismo 475 (El hombre europeo y la destrucción de las naciones) de Humano demasiado humano. Como es bien conocido, el aforismo contiene un elogio abierto de la contribución que los eruditos judíos habían tenido «en los tiempos más oscuros de la Edad Media» y del enfrentamiento al oscurantismo de la Iglesia de Roma, al desarrollo de aquello que Nietzsche designa con el término inequívoco de «iluminismo». En explícita polémica con la propaganda antisemita, que consideraba a los judíos un elemento asiático extraño a Europa ${ }^{55}$, Nietzsche arruina la perspectiva afirmando que «si el cristianismo hizo de todo para orientalizar Occidente, en compensación el judaísmo ha contribuido esencialmente a occidentalizarlo siempre de nuevo». Así, «cuando la capa de nubes asiática se había instalado pesadamente sobre Europa, fueron los librepensadores, los intelectuales y los médicos judíos los que mantuvieron alto el estandarte de la ilustración (das Banner der Aufklärung) y la independencia espiritual bajo las más duras constricciones personales» (MA, KSA, 2, 310-311; OC III 239). La Aufklärung citada por Nietzsche es una clara y directa referencia al libro de Reuter, el cual subraya cómo en Francia, bajo Luis VII y Felipe Augusto, los eruditos judíos habían tenido parte activa en las disputas teológicas, no excluye las heréticas, y habrían contribuido en términos decisivamente concretos: «Unos recurrían a su dinero, otros a su arte médica» ${ }^{56}$.

54 Cfr. G. Campioni-P. D’Iorio-M.C. Fornari-F. Fronterotta-A. Orsucci, op. cit., p. 496; el volumen figura como adquirido el 10 de marzo de 1875 en Basilea.

55 Remito al respecto a mi trabajo L'Europa dei 'senza patria'. I 'buoni europei'e la questione ebraica, en A. Venturelli (ed.), Letteratura e identità europea, Roma: Istituto Italiano di Studi Germanici 2018, pp. 43-65.

56 H. Reuter, Geschichte der religiösen Aufklärung im Mittelalter vom Ende des achten Jahrhunderts bis zum Anfange des vierzehnten, Berlin: Hertz 1875, vol. I, p. 154; cfr. A. Orsucci, Tradizione ebraica e civiltà europea: un passaggio cruciale nell'ottica di Nietzsche, en V. Vivarelli (ed.), Nietzsche e gli ebrei, Firenze: Giuntina 2011, pp. 63 ss.; Orsucci recuerda cómo Reuter se había apropiado de las indicaciones contenidas en el libro de Ernest Renan, Averroès et l'averroïsme, publicado en 1866 
Tal presencia del libro de Reuter, que ejerce su influencia sobre un punto bastante delicado de las reflexiones de Nietzsche, deja suponer que él lo había podido tener presente también respecto a otros contextos. En este sentido, se le puede haber escapado el informe de la disputa entre Fredegiso de Tours y Agobardo de Lyon sobre la relación entre revelación y las Sagradas Escrituras ${ }^{57}$, como también la citación explícita de De nihilo et tenebris a propósito de la relación entre razón y autoridad ${ }^{58}$, más difícil nos resulta imaginar que se le haya escapado el tratamiento relativo a «aquellos que pueden ser definidos los nihilistas de siglo XII» ${ }^{59}$. Su posición se caracterizaba por dos intereses solo aparentemente heterogéneos: por un lado el de la ciencia, por el otro el de la «dialéctica formal» que derivaba de la difusión de las traducciones del Organon aristotélico ya vigentes, a partir de Boecio, en los siglos precedentes. Comenzó así a difundirse un «excéntrico panlogismo» que, precisamente porque consideraba a Aristóteles casi exclusivamente un lógico, pretendía identificar la lógica con la filosofía y a esta con la ciencia ${ }^{60}$. En este periodo, «científico» y «metódico» llegan a ser términos casi equivalentes. Al mismo tiempo se determinó una radical oposición entre lo nuevo y lo antiguo, en la que lo nuevo «llegaba a ser sinónimo de verdadero» ${ }^{61}$. El efecto paradójico de esta conversión lógico-metódica del saber fue, sin embargo, que la unificación de sus diversos ámbitos por obra de la filosofía pura condujo a anular la dimensión puramente teórica de la reflexión en favor de su traducción pragmática. De este modo, si el pensamiento era considerado «como la única función digna del hombre de cultura», sin embargo «la teoría se cambió con la cosa, la doctrina con el objeto, la disposición con la ejecución. Se enseñaba el ethos para superarlo en la práctica; se fijaba la representación religiosa en el concepto para prescindir de la fe» ${ }^{62}$. Con un término que no puede dejar de pensar en Jacobi, Reuter define esta actitud como una «excentridad idealista» que tuvo el efecto paradójico de resolverse «en un sentido práctico (Prakticismus) totalmente no científico». Una parte considerable de estos «nihilistas» «creyó encontrar el saber auténtico solo en las disciplinas exactas. Algunos fueron a Montpellier o a Salerno para estudiar medicina, otros se dedicaron a la física» ${ }^{63}$. Ciertamente, uno estaría tentado a suponer que estas palabras se hayan de alguna manera inspirado en el Bazarov de Turgenev. Nace de esta manera:

57 H. Reuter, op. cit., pp. 36 ss.

58 Ibid., p. 40.

59 Ibid., p. 168.

60 Cfr. Ibid, pp. 168-169.

61 Ibid., p.170.

62 Ibid, p. 171.

63 Ibid, p. 172. 
El partido de aquellos nihilistas cuya protesta contra la autoridad de la Iglesia es suficientemente clara [...] Todo esto que rápidamente se designa como misterio de la fe es desde el principio excluido por ellos del ámbito del saber científico. Ellos no reconocían nada que no pudiese ser explicado a partir del nexo causal con el ser (finito). ${ }^{64}$

En cuanto «maestros de la dialéctica», ellos «se vanagloriaban de conocer» allí donde los otros «se limitaban a creer» ${ }^{65}$; «contraponer fe a razón era para ellos un placer» ${ }^{66}$. Reuter supone que estos nihilistas habían contribuido de una manera importante a lo que él define como el «iluminismo» de la Edad Media ${ }^{67}$.

El hecho de que la tradición y, específicamente, las fuentes de las que se sirve Reuter - Giovanni de Salibsury, Abelardo, Ugo de San Vittore entre otros-, no nos haya trasmitido algún nombre u obra de estos nihilistas se explica con una escrupulosa damnatio memoriae activada contra ellos. «Parece que ellos se hayan llamado a si mismo filósofos», mientras Abelardo, en la Theologia Christiana, los llama «profesores de dialéctica, pseudofilósofos» ${ }^{68}$.

Está suficientemente claro cómo Reuter describe a estos filósofos sobre la base de características tomadas, al menos en parte, del debate filosófico contemporáneo a él. El uso mismo del término «nihilismo» es un evidente anacronismo que mira a la filosofía de su época. En él se encuentran resumidas y aplicadas tanto la polémica antiidealista de Jacobi, como la obsesión científico-positivista del siglo XIX, así como, unida a ella, la vocación ateísta que resuelve la religión en el concepto.

Consideramos que es un ejercicio ocioso ir a buscar referencias textuales sobre el libro de Reuter en la obra de Nietzsche ${ }^{69}$. Pero si consideramos plausible que él haya leído aquellas páginas dedicadas a los «nihilistas» medievales, podíamos suponer que haya encontrado en ellas aquella interpretación filosófica del nihilismo sobre la que él construye su propia crítica de la moral y del conocimiento.

[Traducción: Luis Enrique de Santiago Guervós]

64 Ibid., pp. 173-174.

65 Ibid., p. 174.

66 Ibid., p. 175.

67 Cfr. Ibid., p. 177.

68 Ibid., p. 178.

69 Considérese, sin embargo, como punto de partida de reflexión, lo que Nietzsche escribe en estos dos fragmentos de finales de 1886- primavera de 1887; el primero se refiere al idealismo: «Todo el idealismo de la humanidad está a punto de convertirse en nihilismo - en la creencia en la absoluta falta de valor, es decir, falta de sentido». (7[54], KSA, 12, 313; FP IV 221); el segundo se refiere a la religión: «Se cree poder escapar con un moralismo sin trasfondo religioso: pero con ello el camino al nihilismo es necesario» (7[64], KSA, 12, 318; FP IV 224). 